\title{
Reliability-based assessment of doubly reinforced beams for limit state of collapse
}

\author{
Anadee M. Kulkarni* and Debarati Datta* \\ Department of Applied Mechanics, Visvesvaraya National Institute of Technology, Nagpur 440 010, India
}

This study examines the reliability levels of doubly reinforced beams designed according to the Indian standard code for plain and reinforced concrete (IS456:2000). Mathematical models were developed for limit state of collapse for flexure and shear according to IS456:2000. The resistance was expressed in the form of limit state of equations and the random variables identified were grade of concrete and grade of steel. The significant load variables considered were dead load and live load. Reliability indices were evaluated using first order reliability method. The analysis was carried out on beams designed for different live load intensities. The effect of reinforcement bar diameter and the effect of limit state equations on the reliability indices were evaluated. The results obtained were compared with international standards. This study evaluates the IS456:2000 provision for beam design from the probabilistic and risk-based analysis point of view. Accordingly, some suggestions have been made for setting the target reliability levels for IS456:2000. This analysis aims to initiate the basic application of reliability to design methodology of the code.

Keywords: Beams, flexure, reinforced concrete, reliability indices, shear.

THE reliability of a system or component is the probability of performing its function over a given period of its design life. In recent times, probabilistic analysis or reliability analysis is increasingly being applied in the field of structural engineering. The study of source of randomness in structures has been the main focus in structural engineering, which includes the variability of resistance and loads. This has led to many design guidelines and codes being modified to incorporate reliability-based analysis and design. European design code (Eurocode 2) ${ }^{1}$ has been evaluated for the calculation of safety margin and estimate the target reliability levels of reinforced concrete (RC) structures such as beam and column, for the limit state of collapse ${ }^{2}$. For the Australian and US codes, target reliability index is suggested for serviceability reliabilities for structural steel beams in flexure ${ }^{3}$. A number of serviceability issues related mainly to exces-

*For correspondence. (e-mail: anadee4mk@gmail.com; debaratidatta@apm.vnit.ac.in) sive deflection of structural floor elements such as beams and columns, and field data for serviceability damage have been studied ${ }^{4}$. Studies have examined the reliability of beams exposed to fire ${ }^{5-7}$, since RC structures are vulnerable to high temperature conditions such as those during fire. Also, probabilistic studies for limit state of serviceability of RC beams and steel beams have been carried out ${ }^{4,8-13}$. Reliability of corroded RC beams and columns was reviewed and parametric studies on the serviceability and collapse limit states were done, and the effect on various parameters was observed ${ }^{14}$. Reliabilitybased methodology is also being used in assessing damages in RC structures using statistics of random variables in the limit state functions ${ }^{15}$. The probabilistic concept was applied to Indian code specifications on RC beams for exposure to fire ${ }^{6}$, after designing it according to the limit state design method using IS456:2000 (ref. 16). Reliability analysis of RC beams with respect to limit state of crack width under different loading conditions was carried out using Monte Carlo technique ${ }^{17}$.

For Indian code IS456:2000, reliability analysis of RC beams was carried out using first order reliability method $(\text { FORM })^{18}$, in which important random variables associated with the limit state of flexure and shear were identified. The beams were designed as simply supported, singly reinforced beams (SRBs) for different spans and for dead load and live load, according to IS456:2000. The random variables were identified as grade of steel, grade of concrete, dead load and live load. From FORM analysis, sensitivity of the random variables associated with the limit state functions was assessed and its effect on the reliability index values was estimated. The grade of concrete and dead load were the least significant variables (of the four random variables identified) in limit state of flexure while evaluating the reliability index values. Similarly in limit state of shear (among the three random variables identified), dead load had a minimalistic effect on the reliability index values. The literature is just limited to the assessment of sensitivity of the random variables and does not provide the target reliability levels. The study by Kulkarni and Datta ${ }^{18}$, regarding the importance of random variables in the limit state functions can be further expanded and target reliability levels can be achieved for RC beams using reliability analysis.

The application of risk and reliability in the analysis and design of structural systems is thus popular for 
updating codes of practice in Europe and America. In IS456:2000, the randomness and uncertainty of loads coming on the structural element are taken into account by characteristic loads. Similarly, material uncertainty is addressed by defining characteristic strength. The safety of structure is ensured by partial safety factor for loads and materials. In order to incorporate the risk and reliability factor in the Indian design guidelines, limited studies are available in the literature for a clear understanding of the subject and its application to the design methodology. The Indian Standard code for plain and RC (IS456:2000) needs to be updated to reliability-based design approach. Thus, the present study deals with the basic concept of design of doubly reinforced beams (DRBs) with the application of reliability analysis for the limit state of collapse.

The study aims to determine the reliability levels of DRBs when subjected to dead load and live load with different intensities. This will help determine the reliability index values for DRBs and will thus lead towards setting the target reliability levels which are lacking in the Indian code (IS456:2000) for the design. The effect of the rebar diameter on reliability index is also examined. Values obtained in this analysis are compared made with those in the literature, and conclusions are drawn. The limit state equations for flexure and shear for DRBs are developed and statistical data is obtained. The DRBs are designed for different intensities of loadings and reliability analysis is performed. FORM is used for the reliability analysis, and from the analysis a reliability level is proposed. Suggestions regarding the introduction of reliability index levels have also been proposed.

\section{Design of DRBs}

The DRBs are designed by following the provisions of IS456:2000 for different spans, that is, following the limit state method (LSM), or load and resistance factor design (LRFD) method. The end conditions for the beam design are assumed as simple support. The loading on the beam is initially divided into two loads, viz. residential and commercial. The loads are used without considering the load factors. These loads act on the slabs and through the slabs (loads which include residential/commercial load and self-weight of slab) they are applied on the beams. Along with slab load, the self-weight of beam and wall load are also taken on the beam. The wall load is calculated by assuming $230 \mathrm{~mm}$ thick brick wall, $12 \mathrm{~mm}$ plaster on both sides and $3 \mathrm{~m}$ height with $300 \mathrm{~mm}$ depth of beam for the upper floor, irrespective of exterior or interior beam.

The loads acting on the beam are broadly classified into four categories: (a) Slab from one side (exterior beam; $L 1$ ). (b) Slab from two sides (interior beam; $L 2$ ). (c) Slab from one side with wall load (L3). (d) Slab from two sides with wall load (L4).
Figure 1 shows the different configurations for loading under consideration. Table 1 shows the loads acting on the slab panel ${ }^{19-21}$.

For calculation of loads on the beams, the slab panel was first designed according to the provisions of IS456:2000 and using the parameters shown in Table 2. For the slab panel, it was assumed that the slab is simply supported. The span of the slabs was 4, 4.5, 5, 5.5 and $6 \mathrm{~m}$. The overall thickness of the slab was taken as span/25, conforming to IS456:2000. The slab is acted by live load (residential/commercial) and floor finish. The slab panels have been designed for residential as well as commercial load (Table 1). The slab panel once designed, its load can be applied to the beam. The beams have been designed according to the provisions of IS456:2000 and using the parameters shown in Table 3. By keeping the practical aspects for the design, width of the beam to

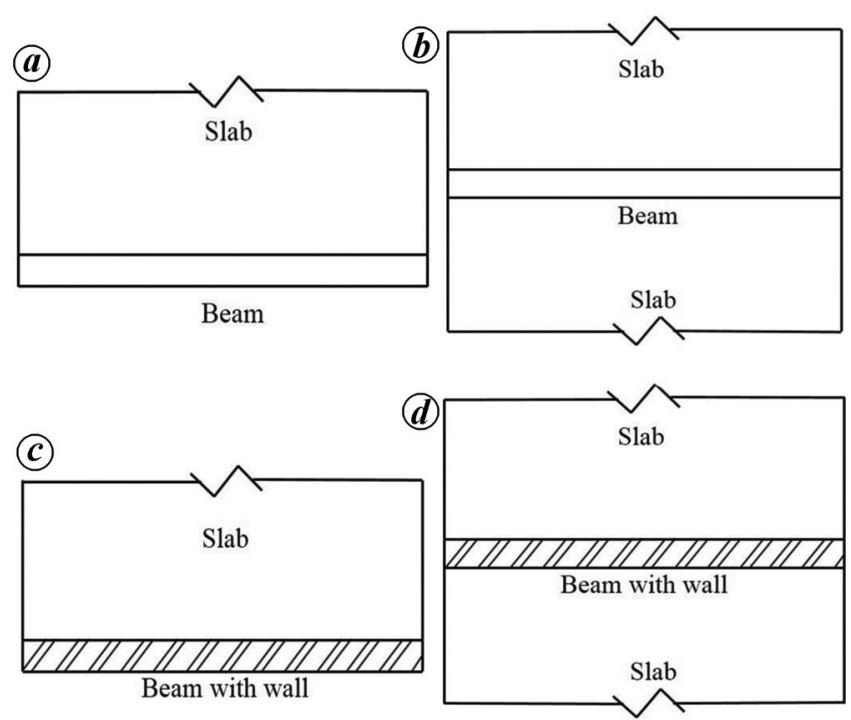

Figure 1. Plan diagrams for the different load scenarios under consideration. $\boldsymbol{a}$, Slab from one side (exterior beam; $L 1$ ). $\boldsymbol{b}$, Slab from two sides (interior beam; $L 2)$. c, Slab from one side with wall load (L3). $\boldsymbol{d}$, Slab from two sides with wall load (L4).

Table 1. Loads acting on the slab panel

\begin{tabular}{lcc}
\hline Load type & Load $\left(\mathrm{kN} / \mathrm{m}^{2}\right)$ & Reference \\
\hline Live load (residential) & 2 & 19 \\
Live load (commercial) & 4 & 19,20 \\
Floor finish & 1 & 20,21 \\
\hline
\end{tabular}

Table 2. Parameters for the design of slab panel

\begin{tabular}{ll}
\hline Parameter & \multicolumn{1}{c}{ Value } \\
\hline Grade of concrete $\left(f_{c}\right)$ & $25 \mathrm{MPa}$ \\
Grade of steel $\left(f_{y}\right)$ & $415 \mathrm{MPa}$ \\
Density of concrete & $25 \mathrm{kN} / \mathrm{m}^{3}$ \\
Slab cover & $15 \mathrm{~mm}$ \\
Initial rebar diameter & $10 \mathrm{~mm}$ \\
\hline
\end{tabular}




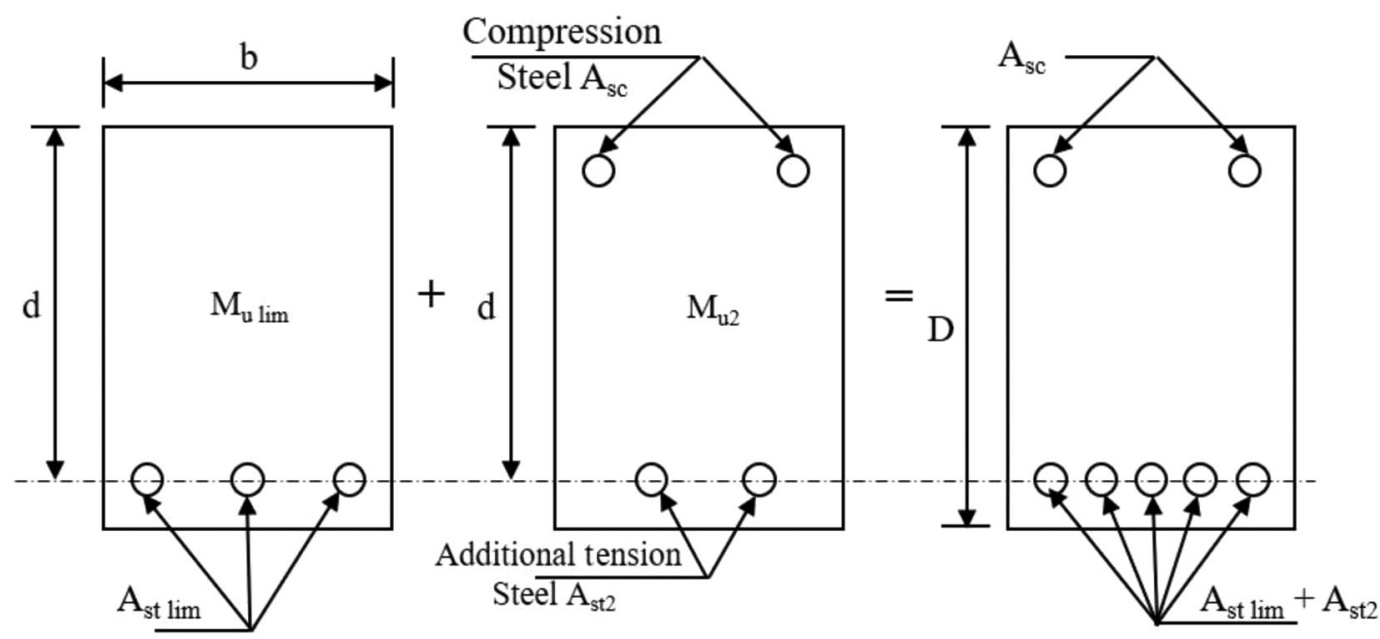

Figure 2. Illustration of steel beam theory.

Table 3. Parameters for the design of doubly reinforced beams

\begin{tabular}{ll}
\hline Parameter & \multicolumn{1}{c}{ Value } \\
\hline Grade of concrete $\left(f_{c}\right)$ & $25 \mathrm{MPa}$ \\
Grade of steel $\left(f_{y}\right)$ & $415 \mathrm{MPa}$ \\
Density of concrete & $25 \mathrm{kN} / \mathrm{m}^{3}$ \\
Nominal beam cover & $20 \mathrm{~mm}$ \\
$\quad$ (mild conditions) & $12,16,20,25,30,32 \mathrm{~mm}$ \\
Rebar diameters & Two-legged, $8 \mathrm{~mm}$ diameter \\
Stirrups & $0.75 \mathrm{~d}$ or $300 \mathrm{~mm}$, whichever is less \\
Spacing of stirrups $\left(s_{v}\right)$ &
\end{tabular}

overall depth ratio $(b / D)$ was maintained between 0.5 and 0.67 (ref. 22).

DRBs are used wherever there is constraint of space. In such cases, the dimensions of the beams are to be restricted. Therefore, some restrictions have been assumed for the design. The width of the beam was $200 \mathrm{~mm}$ and depth 300, 350 and $400 \mathrm{~mm}$. The DRBs were also checked for serviceability criteria according to the provisions of IS456:2000. Thus, if the beams did not satisfy the deflection check, the depth of the beams was increased. The beams were subjected to different load intensities and designed according to the provisions of the IS code. Initially the beams were designed for lengths of 4, 4.5, 5, 5.5 and $6 \mathrm{~m}$, and classified as SRBs or DRBs. Only the DRBs were selected and limit state functions are developed for the designed beams (for each loading condition) for reliability analysis.

\section{Limit state of flexure}

The behaviour of RC beams with compression steel for ultimate load design is referred to as the steel beam theory (Figure 2). The real beam is assumed to consist of two beams, namely an SRB which reaches its ultimate strength by failure of concrete in compression, and a steel beam without any concrete but only compression and tension steel (Figure 2). The moment of resistance of a DRB will be the sum of moment of the resistance of the two beams, as shown in eq. (1). The FORM methodology used is explained in Appendix 1.

$$
\begin{aligned}
& M_{u}=M_{u \lim }+M_{u 2}, \\
& g(x)=M_{u \lim }+M_{u 2}-M_{u}=0 .
\end{aligned}
$$

Equation (2) is equal to zero, since $A_{\text {st }}$ (provided) is equal to $A_{\text {st }}$ (required) and $A_{\mathrm{sc}}$ (provided) is equal to $A_{\mathrm{sc}}$ (required). $M_{\mathrm{u} \text { lim }}$ (or $M_{\mathrm{u} 1}$ ) is the limiting moment of resistance which gives the reinforcement for a SRB $\left(A_{\mathrm{st} \text { lim }}\right)$ for tension, $M_{\mathrm{u} 2}$ is the moment of resistance due to compression because of equal and opposite compression and tension forces, and gives the compression as well as tension steel ( $A_{\mathrm{sc}}$ and $\left.A_{\mathrm{st} 2}\right)$ to balance the section. Therefore, the total steel in tension will be $\left(A_{\mathrm{st}}=A_{\mathrm{st} \mathrm{lim}}+A_{\mathrm{st} 2}\right)$.

$$
\begin{aligned}
& M_{u \lim }=0.138 f_{\mathrm{c}} b d^{2}(\text { for Fe415 steel }) \\
& M_{u 2}=A_{\mathrm{st} 2}\left(0.87 f_{y}\right)\left(d-d^{\prime}\right)
\end{aligned}
$$

where $d^{\prime}$ is the effective cover of concrete for the compression zone.

$$
A_{\mathrm{sc}}\left(f_{\mathrm{sc}}\right)=A_{\mathrm{st} 2}\left(0.87 f_{y}\right)
$$

where $f_{\mathrm{sc}}$ is stress in compression steel reinforcement. Equations (4) and (5) can be used to get $A_{\mathrm{sc}}$ and $A_{\mathrm{sc} 2}$. SP16 gives the values of $f_{\text {sc }}$ for different values of $\left(d^{\prime} / d\right)$ for $\mathrm{Fe} 415$ grade of steel $^{23}$; for the calculation of $A_{s c}$ there is negligible difference for different values of $f_{\text {sc }}$. Therefore, the value of $f_{\text {sc }}$ has been assumed as $353 \mathrm{~N} / \mathrm{mm}^{2}$. The random variables identified were grade of concrete, grade of steel, live load and dead load for limit state of flexure. 


\section{Limit state of shear}

Resistance against shear for beam (IS456:2000) is given by

$$
V_{\mathrm{R}}=\tau_{\mathrm{c}} b d+V_{\mathrm{us}},
$$

where $\tau_{\mathrm{c}}$ is shear strength of concrete and is calculated according to IS456:2000. $V_{\text {us }}$ is the shear resistance given by shear reinforcement.

$$
V_{\mathrm{us}}=\frac{f_{y} A_{\mathrm{sv}} d}{s_{v}},
$$

where $s_{\mathrm{V}}$ is the spacing of stirrups and $A_{\mathrm{sv}}$ is the area of shear reinforcement.

Shear force due to external load is calculated as

$$
V_{\mathrm{s}}=\frac{\left(w_{l}+w_{d}\right)}{2} l \text {. }
$$

The random variables identified were grade of steel, live load and dead load for limit state of shear.

\section{Reliability analysis}

The reliability analysis has been divided in two main sections: (i) reliability analysis for limit state of flexure, and (ii) reliability analysis for limit state of shear. In these sections, the work is again divided according to the loading acting on the beam, viz. residential load and commercial load (Table 1). According to the loading, the beams have been designed using specifications of IS456:2000. The failure functions were developed based on Indian codes and the literature ${ }^{6,16,24}$.

\section{Statistical data}

For Indian conditions, statistical data for material properties and loadings are given in Ranganathan ${ }^{24}$ and Balaji et $a l .{ }^{6}$. Table 4 provides the statistical data for material properties and loadings of the beam under consideration.

\section{Reliability analysis for limit state of flexure}

Limit state equation of flexure for DRBs is given by eq (9) (ref. 6). This equation is based on ACI 318-2005 (ref.

Table 4. Statistical distribution of random variables of the beam ${ }^{6,24}$

\begin{tabular}{llcc}
\hline & & \multicolumn{2}{c}{ Parameter } \\
\cline { 3 - 4 } Variables & Distribution type & Mean & COV \\
\hline$f_{y}(\mathrm{MPa})$ & Normal & 468.9 & 0.05 \\
$f_{c}(\mathrm{MPa})$ & Normal & 30.28 & 0.145 \\
$w_{\mathrm{l}}(\mathrm{kN} / \mathrm{m})$ & Extreme largest, type-1 & 10 & 0.3 \\
& (Gumble Max $)$ & & \\
$w_{\mathrm{d}}(\mathrm{kN} / \mathrm{m})$ & Normal & $5+$ self weight & 0.05 \\
\hline
\end{tabular}

$f_{y}$, Grade of steel; $f_{c}$, Grade of concrete; $w_{\mathrm{l}}$, Live load; $w_{\mathrm{d}}$, Dead load.
25), which considers equivalent stress block distribution (stress block) to replace the more exact concrete stress distribution. In equivalent stress block, average stress of $0.85 f_{\mathrm{c}}$ is used with a rectangle. Whereas IS456:2000 uses the stress block distribution by considering it to be in two sections, as rectangle and parabolic. By considering the average stress of $0.85 f_{\mathrm{c}}$ for the rectangular block, eq. (2) is reduced to eq. (9) and is used as limit state equation for flexure for DRBs. Equation (9) is derived after the removal of all the factors of safety for grade of concrete and steel.

$$
\begin{aligned}
g(x)= & f_{y} A_{\mathrm{st}}\left(d-d^{\prime}\right)+\left(A_{\mathrm{st}}-A_{\mathrm{sc}}\right) f_{y} \\
& \times\left(d-\frac{A_{\mathrm{st}} f_{y}}{1.7 f_{\mathrm{c}} b}\right)-\frac{\left(w_{l}+w_{d}\right)}{8} l^{2}, \\
A_{\mathrm{st} 1}= & \frac{P_{t \lim } b d}{100},
\end{aligned}
$$

where $p_{t \lim }$ is the percentage of steel due to tension for balanced section. According to SP16, $p_{t \lim }$ is $1.19 \%$ for $\mathrm{M} 25$ and $\mathrm{Fe} 415$.

FORM was used for analysis with the software package COMREL (version 9) ${ }^{9,26}$. Accordingly, the results of the reliability analysis were obtained. Figures 3 and 4 show the effect of reinforcement bar diameter on the reliability indices.

From Figures 3 and 4, it can be observed that DRBs designed for residential load and commercial load with varying load intensities are highly safe for limit state of flexure. For some beam lengths and load cases, there are no curves, indicating that the beams for those cases are SRBs. For $L=4 \mathrm{~m}$ in residential as well as commercial load cases, the beams are SRBs. Similarly, for some lengths, only $L 3$ and $L 4$ cases are present as for $L 1$ and $L 2$ cases; the beams designed are SRBs.

For $L 1$ case, the reliability index values are less when compared to the $L 4$ case. The reason is that due to increase in loading, the beam section size increases along with steel reinforcement when designed according to IS456:2000. Thus, the reliability index values also increase, indicating that the beams are safe for higher loading. The values of reliability index fluctuate as there is lack of any specific reliability level mentioned in the code for the design.

\section{Reliability analysis for limit state of shear}

Failure function for limit state of collapse with respect to shear using eqs (6)-(8) is given by eq. (11), which is derived after removal of all the factors of safety for grade of steel.

$$
g(x)=\tau_{\mathrm{c}} b d+\frac{f_{y} A_{\mathrm{sv}} d}{s_{v}}-\frac{\left(w_{l}+w_{d}\right)}{2} l .
$$



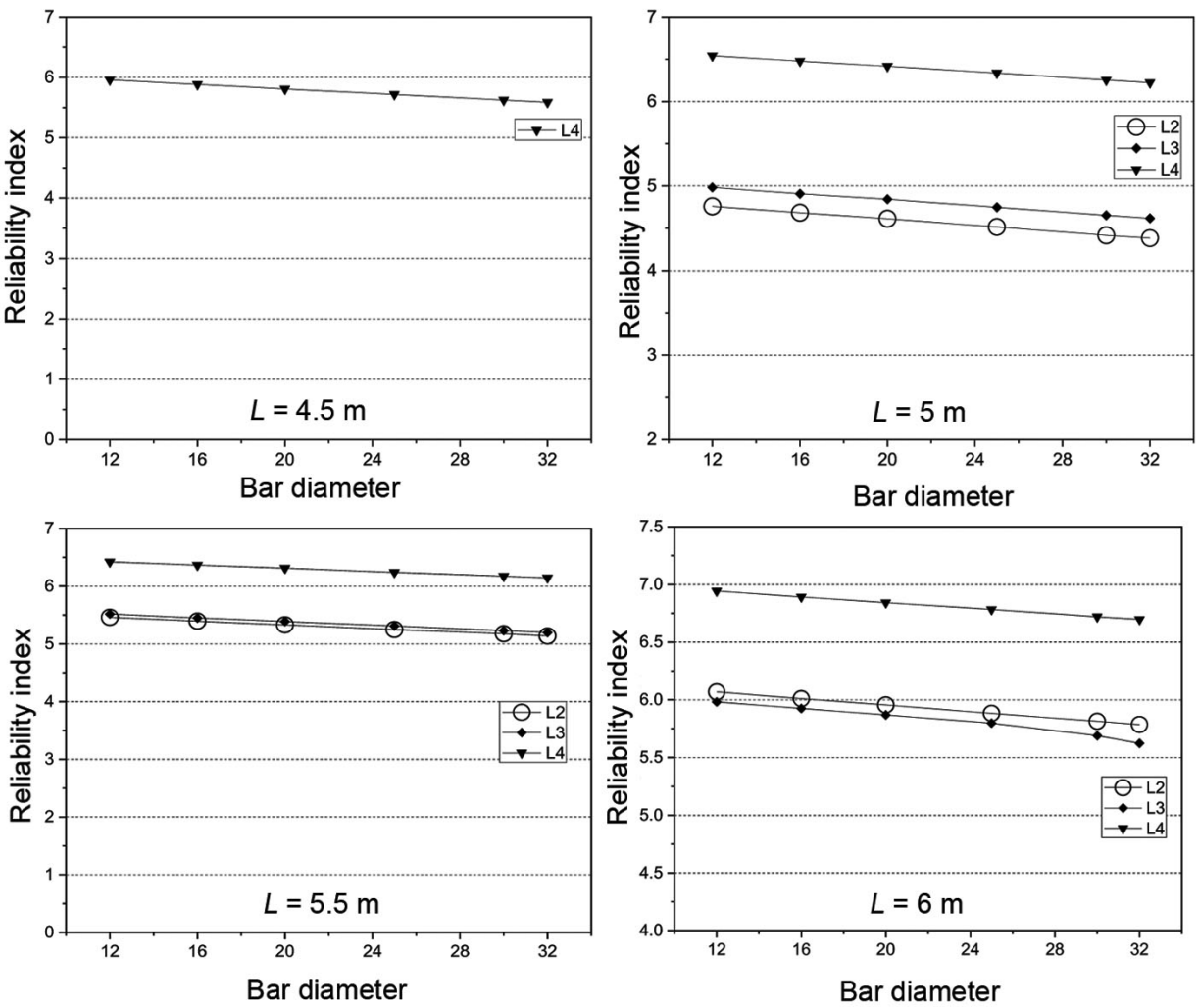

Figure 3. Effect of bar diameter on reliability index (residential load) for flexure (DRBs).
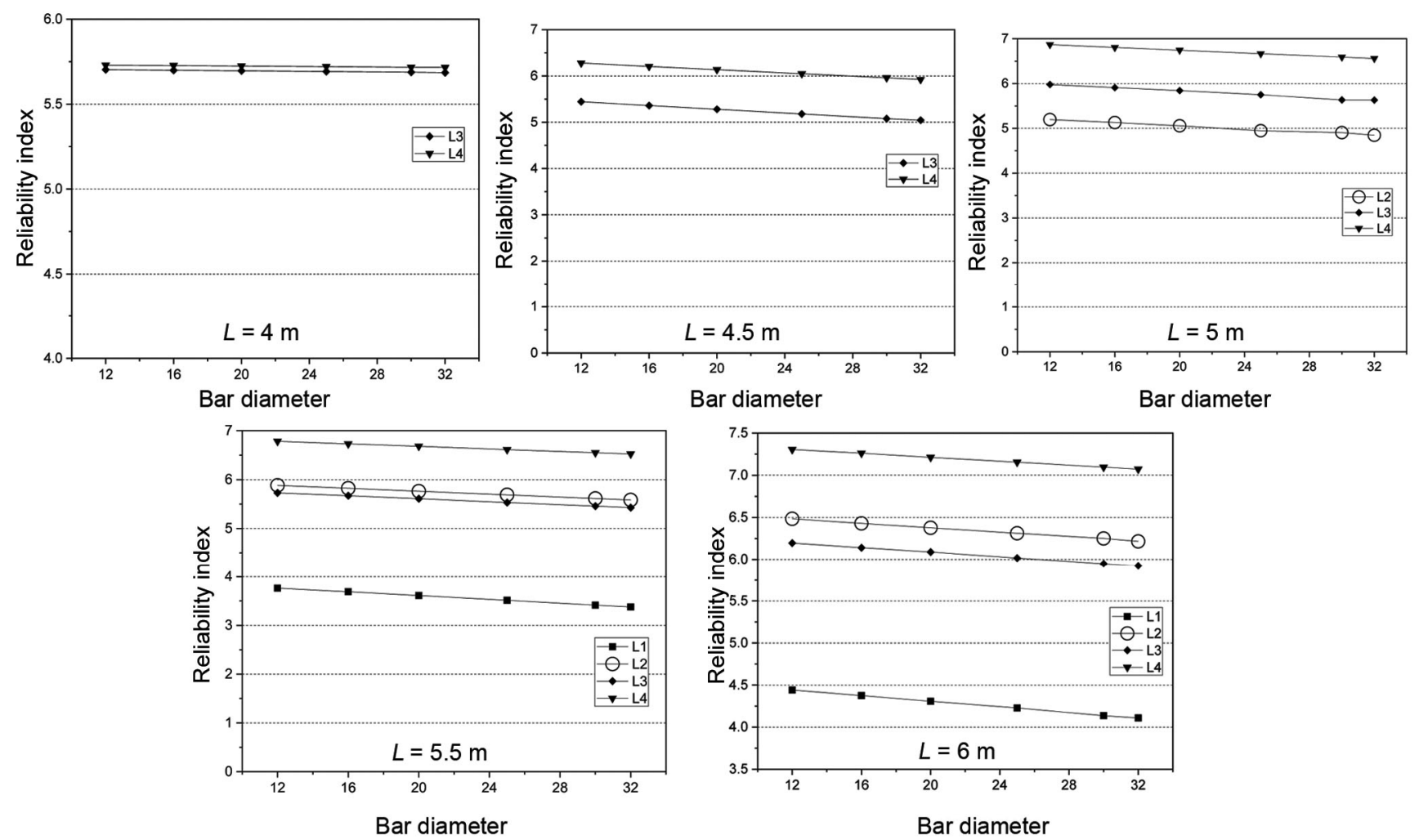

Figure 4. Effect of bar diameter on reliability index (commercial load) for flexure (DRBs). 
RESEARCH ARTICLES
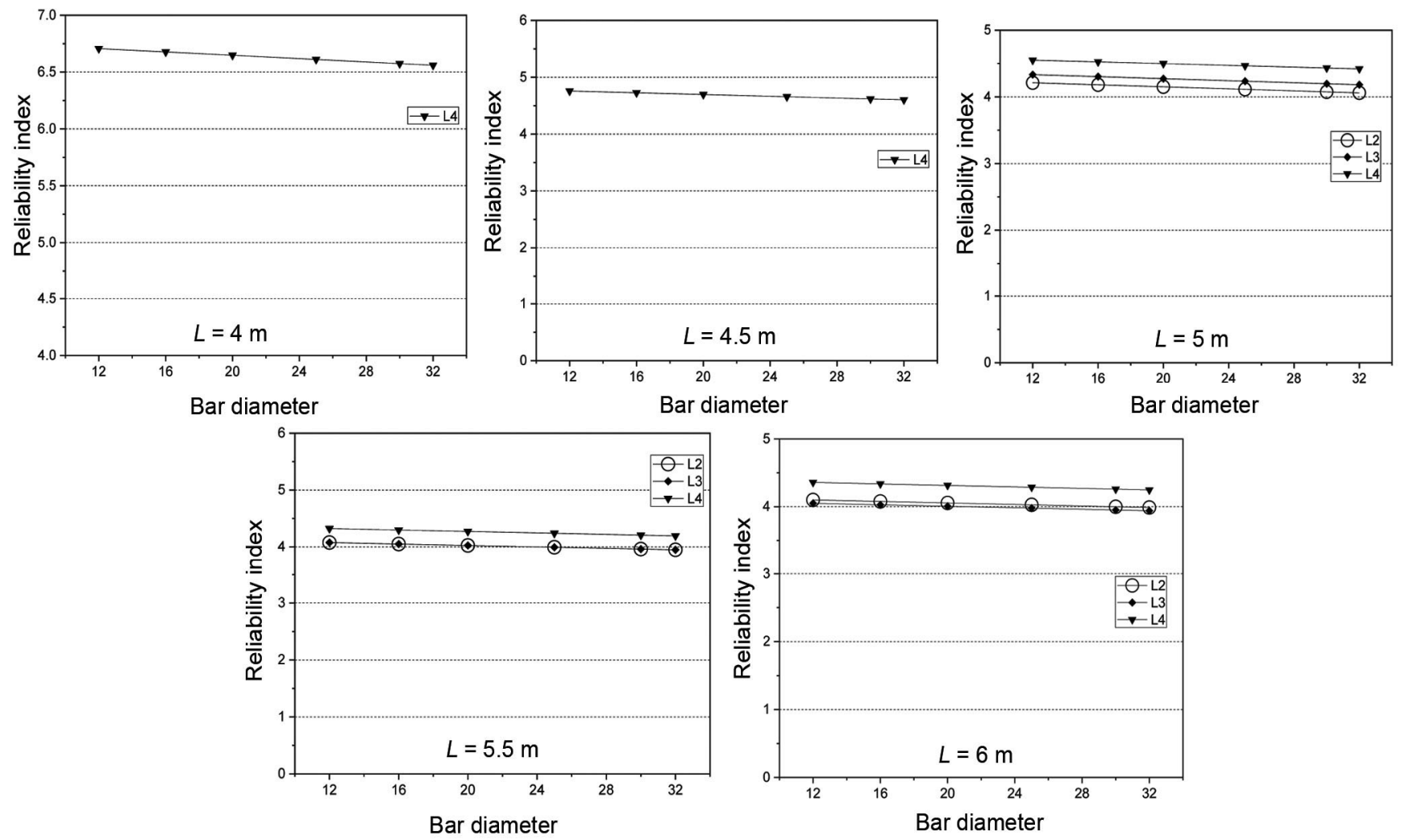

Figure 5. Effect of bar diameter on reliability index (residential load) for shear (DRBs).
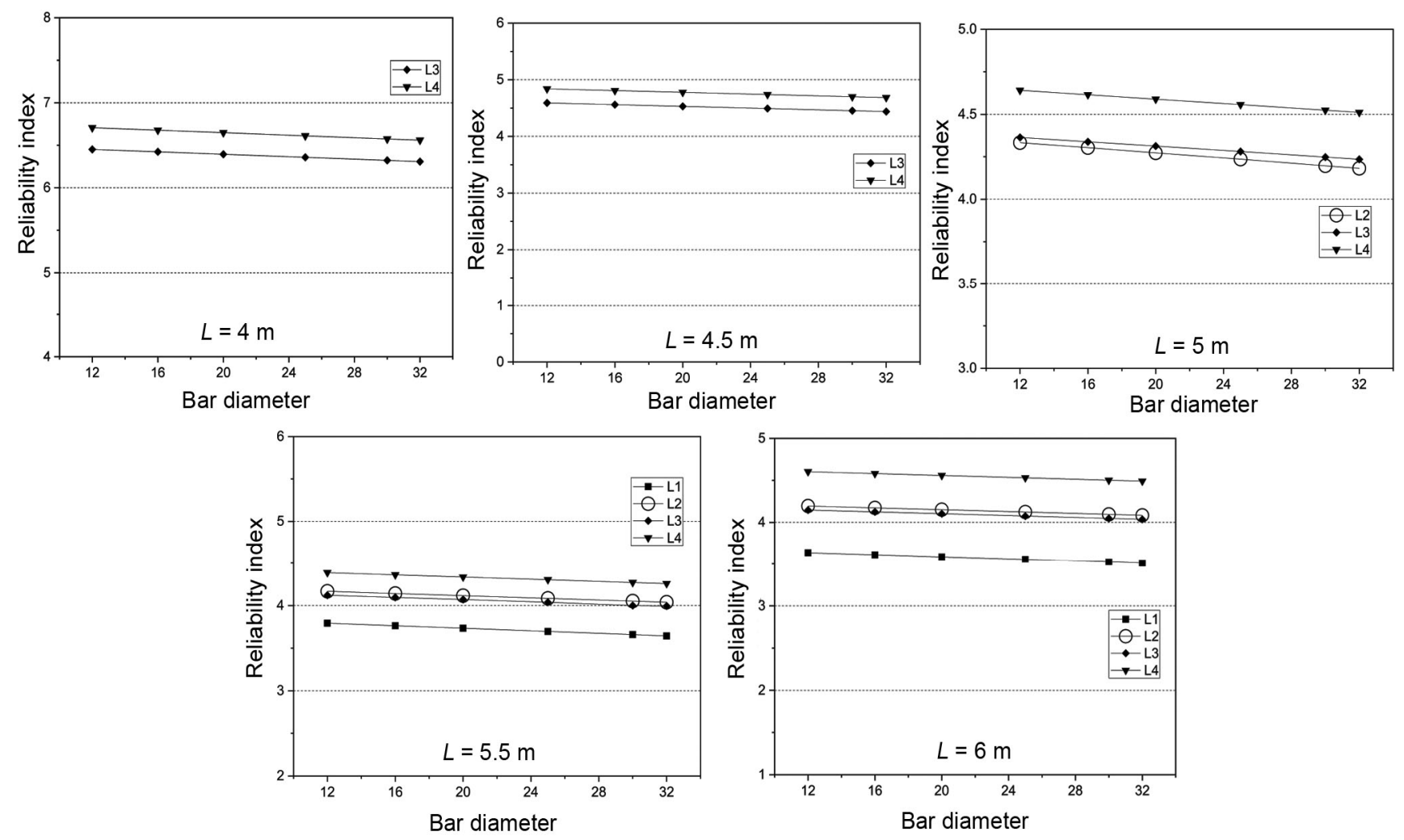

Figure 6. Effect of bar diameter on reliability index (commercial load) for shear (DRBs). 


\section{RESEARCH ARTICLES}

Accordingly, results for the reliability analysis are obtained. Using these results, the effect of reinforcement bar diameter is studied on the reliability indices (Figures 5 and 6$)$.

As for flexure, in shear also initially during the designing process, according to the different load intensities applied, the beams are classified as SRBs or DRBs. For DRBs, reliability analysis is carried out according to the limit state equations for shear.

Figures 5 and 6 show that for different types of loading for limit state of shear, the reliability index values change for beams designed according to IS456:2000. When the loads are changed, the reliability index values also change. If the loads are increased (in case of $L 1$ to $L 2$ ), then the beams designed are safer (higher index values) in $L 2$ as compared to $L 1$, as the index values are more in $L 2$ loading condition. In case of limit state of shear also, the values of reliability index fluctuate as there is lack of any specific reliability level mentioned in the code for the design.

\section{Effect of rebar diameter}

The effect of change of rebar diameter on the reliability indices is discussed here. For each load variation, that is, for residential and commercial with different intensities ( $L 1, L 2, L 3$ and $L 4$ cases), rebar diameter of tension reinforcement was varied from $12 \mathrm{~mm}$ and $32 \mathrm{~mm}$ for lengths $4 \mathrm{~m}$ to $6 \mathrm{~m}$. This was done to check the effect of rebar diameter on the reliability indices. This is because with change in rebar diameter there is change in the effective depth of the beam section, which leads to change in the area of tension and compression reinforcement. Therefore, for each change in rebar diameter, there will be a new value of reliability index as there will be changes in the limit state equations. Tables 5-8 show percentage change (with respect to $12 \mathrm{~mm}$ ) in reliability indices for change in diameter from $12 \mathrm{~mm}$ and $32 \mathrm{~mm}$ only, that is, for the minimum and maximum rebar diameter used for the design, for residential as well as commercial loadings for limit state of flexure and shear.

\begin{tabular}{|c|c|c|}
\hline Length (m) & Load type & $\%$ Change \\
\hline 4.5 & L4 & 6.21 \\
\hline \multirow[t]{3}{*}{5} & L2 & 7.88 \\
\hline & L3 & 7.27 \\
\hline & L4 & 4.89 \\
\hline \multirow[t]{3}{*}{5.5} & L2 & 5.90 \\
\hline & L3 & 5.82 \\
\hline & L4 & 4.27 \\
\hline \multirow[t]{3}{*}{6} & L2 & 4.65 \\
\hline & L3 & 6.00 \\
\hline & L4 & 3.54 \\
\hline
\end{tabular}

Table 6. Percentage change for flexure (commercial; DRBs)

\begin{tabular}{lcc}
\hline Length (m) & Load type & \% \\
\hline 4 & L3 & 0.32 \\
& L4 & 0.23 \\
4.5 & L3 & 7.33 \\
& L4 & 5.68 \\
5 & L2 & 6.72 \\
& L3 & 5.80 \\
& L4 & 4.48 \\
& L4 & 3.19 \\
5.5 & L1 & 10.28 \\
& L2 & 5.08 \\
& L3 & 5.25 \\
& L4 & 3.83 \\
6 & L1 & 7.45 \\
& L2 & 4.13 \\
& L3 & 4.41 \\
& L4 & 3.19 \\
\hline
\end{tabular}

Table 7. Percentage change for shear (residential; DRBs)

\begin{tabular}{lcc} 
Length (m) & Load type & \% Change \\
\hline 4.5 & L4 & 3.24 \\
5 & L2 & 3.59 \\
& L3 & 3.48 \\
& L4 & 2.84 \\
5.5 & L2 & 3.12 \\
& L3 & 3.12 \\
& L4 & 2.98 \\
6 & L2 & 2.71 \\
& L3 & 2.72 \\
& L4 & 2.55 \\
\hline
\end{tabular}

Table 8. Percentage change for shear (commercial; DRBs)

\begin{tabular}{lcc}
\hline Length (m) & Load type & \% Change \\
\hline 4 & L3 & 2.22 \\
& L4 & 2.18 \\
4.5 & L3 & 3.31 \\
& L4 & 3.18 \\
5 & L2 & 3.48 \\
& L3 & 2.96 \\
& L4 & 2.80 \\
5.5 & L1 & 3.95 \\
& L2 & 3.07 \\
& L3 & 3.08 \\
6 & L4 & 2.94 \\
& L1 & 3.46 \\
& L2 & 2.65 \\
& L3 & 2.68 \\
& L4 & 2.43 \\
\hline
\end{tabular}


From Tables 5-8 it can be observed that percentage change in reliability indices is negligible (below 10), when diameter of rebar is changed from 12 to $32 \mathrm{~mm}$. Thus, the effect of rebar diameter is a less significant factor in the limit state equations and its effect can be ignored during reliability analysis.

\section{Effect of limit state equations on reliability indices for $D R B s$}

The reliability analysis was carried out for limit state of flexure and limit state of shear. In the former, the variables were grade of concrete, grade of steel and dead load and live load. Whereas in the latter, all the above variables were present, except grade of concrete. We estimated percentage change in the values of reliability indices for shear with respect to limit state of flexure. This is done to give an idea, if the reliability indices in limit state of flexure are calculated, then where an average percentage value of the reliability index in limit state of shear will lie. The average percentage change in the index values for the study was 20.58 . This will provide an estimate of the index values for limit state of shear when those for the limit state of flexure are calculated. Table 9 shows the average percentage change for residential as well as commercial loading according to the length of beam.

\section{Critical observations for reliability index values}

The total number of beams designed was 480 . The beams were classified as SRBs or DRBs. It was observed that 306 beams were DRBs and these were analysed for reliability using FORM. From the number of index values, statistical analysis was carried out in order to estimate target levels for the Indian Standard. Table 10 shows various parameters related to the index values obtained from the analysis. The values shown are irrespective of the type of loading and intensity.

It is clear from Table 10 that the standard deviation values are low, indicating that there is less dispersion of the values. Table 11 shows the values of target reliability adopted by various international codes for $\mathrm{RC}$ design of

Table 9. Percentage change for limit state of flexure and shear (residential and commercial; DRBs)

\begin{tabular}{lc}
\hline Length $(\mathrm{m})$ & \% Change \\
\hline 4 & 6.96 \\
4.5 & 18.31 \\
5 & 20.49 \\
5.5 & 25.46 \\
6 & 31.68 \\
Average & 20.58 \\
\hline
\end{tabular}

members according to LRFD or LSM for limit state of collapse.

Thus, for setting the target reliability levels for IS456:2000, a comparison was made with similar parameters in international standards and codes. The values obtained in this study (average $\beta$ is 5.09) are slightly higher when compared with the maximum value of 4.3 proposed by CEN (2002) ${ }^{1}$ and ISO $13822(2010)^{27}$, as higher index may have an impact on the overall construction cost of the members. Therefore, in order to match the international standards, a moderate value of 4 has been proposed as the target reliability level for the design.

\section{Summary of results}

- For change in rebar diameter from $12 \mathrm{~mm}$ and $32 \mathrm{~mm}$ for lengths 4-6 m for limit state of flexure, the change in reliability index is negligible. It is found out that the average percentage change in reliability index values is 5.02 .

- For change in rebar diameter from $12 \mathrm{~mm}$ and $32 \mathrm{~mm}$ for lengths 4-6 m for limit state of shear, the change in reliability index is negligible. It is found out that the average percentage change in reliability index values is 2.96.

- The percentage change in reliability index values for shear with respect to limit state of flexure is 20.58 . If the values of index for limit state of flexure are known, then we can estimate the values for limit state of shear.

- From the overall analysis irrespective of loading conditions, the minimum value of reliability index in the limit state of flexure is 4.11 and maximum value is 7.30 , and for limit state of shear it is 3.51 and 6.7 respectively. Thus, the values are highly fluctuating and lack of uniformity.

- With increasing load on the beams, that is from $L 1$ to $L 2, L 1$ to $L 3$ or $L 3$ to $L 4$, they had higher reliability

Table 10. Statistical analysis of reliability index values for DRBs

\begin{tabular}{lc}
\hline Parameters & Values \\
\hline Average $\beta$ in limit state of flexure & 5.70 \\
Average $\beta$ in limit state of shear & 4.48 \\
Overall average $\beta$ & 5.09 \\
Standard deviation of $\beta$ in limit state of flexure & 0.82 \\
Standard deviation of $\beta$ in limit state of shear & 0.79 \\
Overall standard deviation of $\beta$ & 1.01 \\
\hline
\end{tabular}

$\beta$, Reliability index.

Table 11. Target reliability indices for limit state of collapse in various codes and standards

\begin{tabular}{lc}
\hline Code & Target reliability index \\
\hline ACI $(2011)^{25}$ & $2.5-4$ \\
Chinese standards $(2011)^{28}$ & $2.7-4.2$ \\
CEN $(2002)^{1}$ & $3.3,3.8$ or 4.3 \\
ISO 13822 $(2010)^{27}$ & $2.3-4.3$ \\
\hline
\end{tabular}




\section{RESEARCH ARTICLES}

indices indicating that the beams are safe for higher loads as the designed sections had more load-carrying capacity. This is observed in both the limit state functions of flexure and shear. Similarly, when loading cases of $L 2$ and $L 4$ are compared, the beams are more safe in $L 4$ than $L 2$. This is because of increased moments, which lead to higher section size and more reinforcement steel in the beams. Thus the beams have higher reliability indices.

- In most of the cases it was observed that the beams are safe (higher reliability index) in case of limit state of flexure than limit state of shear.

\section{Conclusion}

Reliability analysis was carried out for DRBs designed according to the provisions of IS456:2000. The beams were designed for different load intensities and load scenarios. It was observed that the rebar diameter had a negligible effect on the reliability index for limit state of flexure and shear, and thus the effect of rebar diameter can be considered as a passive variable here. When the beams are designed according to the provisions of IS456:2000, there are disparities in the reliability index values for limit state of flexure and shear. The code does not mention the target reliability levels when compared with international codes and standards, which mention reliability index values between 2.3 and 4.3 for limit state design of RC concrete members. The specification of target values for the design of beams according to IS456:2000, will lead to uniformity in the design and can serve as a proof check for the design process. There is the need for specification of these levels, as low reliability levels can result in problems (e.g. collapse, cracking, vibration) and high reliability levels can prove expensive. From the study, and taking into consideration the results for reliability indices obtained for DRBs, we propose a target reliability index value of 4 for DRB design in accordance with international standards. This is a small step to the introduction of reliability levels in the Indian code design specifications, and more measures are necessary for the introduction of risk and reliability. The next process can be identification of reliability classes as in CEN (2002) ${ }^{1}$ and for each class according to reference period, minimum values of reliability index can be defined.

\section{Appendix 1.}

\section{FORM methodology}

Reliability analysis is defined as a probabilistic approach to determine safety level of a system or structure to perform its functions under given conditions. The basic step for the reliability analysis using first order reliability method (FORM) is the formulation of failure functions based on various failure criteria using the relevant load and resistance parameters, known as variables $X_{i}$, in the form of $g(x)=R-S$, where $R$ is the resistance and $S$ is the action, and can be represented as follows

$$
Z=g\left(X_{1}, X_{2}, \ldots, X_{n}\right)
$$

The failure function or limit state of interest can then be defined as $Z=0$. This is the boundary between the safe and unsafe regions in the design parameter space, and it also represents a state beyond which a structure or component can no longer fulfil the function for which it was designed.

$$
\beta=-\frac{\sum_{i=1}^{n} x_{i}^{*}\left(\frac{\partial g}{\partial X_{i}}\right)^{*}}{\sqrt{\sum_{i=1}^{n}\left(\frac{\partial g}{\partial X_{i}}\right)^{2 *}}}
$$

where $\left(\partial g / \partial X_{\mathrm{i}}\right)^{*}$ is the $i$ th partial derivative evaluated at the design point with coordinates $\left(x_{1}^{*}, x_{2}^{*}, \ldots, x_{n}^{*}\right)$. The design point is given by

$$
x_{i}^{*}=-\alpha_{i} \beta
$$

where

$$
\alpha_{i}=\frac{\left(\frac{\partial g}{\partial X_{i}}\right)^{*}}{\sqrt{\sum_{i=1}^{n}\left(\frac{\partial g}{\partial X_{i}}\right)^{2 *}}}
$$

where $\alpha_{\mathrm{i}}$ are the direction cosines which give the sensitivity of the random variables in the limit state equation. By knowing the sensitivity, the number of random variables can be reduced. Using eq. (A3), design point is given by

$$
x_{i}^{*}=\mu_{x_{i}}-\alpha_{i} \sigma_{x_{i}} \beta .
$$

Following are the steps to evaluate $\beta$ for a limit state equation:

Step 1. Define an appropriate limit state function.

Step 2. Assume initial values of design point $x_{i}^{*}$.

Step 3. Evaluate $\left(\partial g / \partial X_{\mathrm{i}}\right)^{*}$ and $\alpha_{\mathrm{i}}$ at $x_{i}^{*}$.

Step 4. Obtain a new design point $x_{i}^{*}$ in terms of $\beta$ as in eq. (A3).

Step 5. Substitute the new $x_{i}^{*}$ in limit state equation $g\left(x_{i}^{*}\right)=0$ and solve for $\beta$.

Step 6. Using the $\beta$ value obtained in step 5, reevaluate $x_{i}^{*}=-\alpha_{i} \beta$.

Step 7. Repeat steps 3 through 6 until $\beta$ converges.

CURRENT SCIENCE, VOL. 119, NO. 6, 25 SEPTEMBER 2020 
The probability of failure in terms of reliability index $\beta$ is given as follows

$$
p_{\mathrm{f}}=\Phi(-\beta)=1-\Phi(\beta)
$$

where $\Phi$ is the cumulative distribution function of the standard normal variate. Alternatively, $p_{\mathrm{f}}$ is the same as given below when failure occurs $(Z<0)$

$$
p_{\mathrm{f}}=\int \ldots \int_{g()<0} f_{X}\left(x_{1}, x_{2}, \ldots, x_{n}\right) \mathrm{d} x_{1} \mathrm{~d} x_{2} \ldots \mathrm{d} x_{n},
$$

In which $f_{X}\left(x_{1}, x_{2}, \ldots, x_{n}\right)$ is joint probability density function for the basic random variables $X_{1}, X_{2}, \ldots, X_{n}$ and integration is performed over the failure region $g()<0$.

1. CEN (European Committee for Standardization), Eurocode: Basis of design, EN 1990, Brussels, Belgium, 2002.

2. Delgado, J., de Azeredo, M. and Delgado, R., Probability of failure estimation of current reinforced structures using the Latin hypercube sampling. WIT Trans. Ecol. Environ., 2000, 45.

3. Stewart, M. G., Optimization of serviceability load combinations for structural steel beam design. Struct. Saf., 1996, 18(2), 225238; https://doi.org/10.1016/0167-4730(96)00012-4.

4. Hossain, N. B. and Stewart, M. G., Probabilistic models of damaging deflections for floor elements. J. Perform. Construct. Facilities, 2000, 15(4), 135-140; https://doi.org/10.1061/(ASCE)08873828(2001)15:4(135).

5. Eamon, C. D. and Jensen, E., Reliability analysis of RC beams exposed to fire. J. Struct. Eng., 2013, 139(2); https://doi.org/ 10.1061/(ASCE)ST.1943-541X.0000614.

6. Balaji, A., Aathira, M. S., Pillai, T. M. and Nagarajan, P., Reliability studies on RC beams exposed to fire based on IS456:2000 design methods. Struct. Eng. Mech., 2016, 59(5), 853-866; http://dx.doi.org/10.12989/sem.2016.59.5.853.

7. Kmet, S., Tomko, M., Demjan, I., Pesek, L. and Priganc, S., Analysis of a damaged industrial hall subjected to the effects of fire. Struct. Eng. Mech., 2016, 58(5), 757-781; http://dx.doi.org/ 10.12989/sem.2016.58.5.757.

8. Galambos, T. V. and Ellingwood, B., Serviceability limit states: deflection. J. Struct. Eng., 1986, 112(1); https://doi.org/10.1061/ (ASCE)0733-9445(1986)112:1(67).

9. Honfi, D., Martensson, A. and Thelandersson, S., Reliability of beams according to Eurocodes in serviceability limit state. Eng. Struct., 2012, 35, 48-54; https://doi.org/10.1016/j.engstruct. 2011.11.003.

10. Stewart, M. G., Serviceability reliability analysis of reinforced concrete structures. J. Struct. Eng., 1996, 122(7); https:// doi.org/10.1061/(ASCE)0733-9445(1996)122:7(794).
11. Khor, E. H., Rosowsky, D. V. and Stewart, M. G., Probabilistic analysis of time-dependent deflections of RC flexural members. Comput. Struct., 2001, 79(16), 1461-1472.

12. Torii, A. J. and Machado, R. D., Reliability analysis of nonlinear reinforced concrete beams subject to ageing effects. Mec. Comput., 2012, XXIX, 6847-6863.

13. Lu, R., Luo, Y. and Conte, J. P., Reliability evaluation of reinforced concrete beams. Struct. Saf., 1994, 14(4), 277-298.

14. El-Reedy, M. A., Reinforced Concrete Structural Reliability, CRC Press, Boca Raton, FL, USA, 2012.

15. Sakka, Z. I., Assakkaf, I. A. and Qazweeni, J. S., Reliability-based assessment of damaged concrete buildings. Struct. Eng. Mech., 2018, 65(6), 751-760; http://dx.doi.org/10.12989/sem.2018.65.6.751.

16. BIS, IS456:2000, Plain and reinforced concrete - code of practice (fourth revision), Bureau of Indian Standards, New Delhi, 2000.

17. Desayi, P. and Rao, K. B., Reliability of reinforced concrete beams in limit state of cracking - failure rate analysis approach. Mater. Struct., 1989, 22(4), 269-279; https://doi.org/10.1007/ BF02472559.

18. Kulkarni, A. M. and Datta, D., Probabilistic analysis of RC beams according to IS456:2000 in limit state of collapse. Struct. Eng. Mech., 2019, 71(2), 165-173; https://doi.org/10.12989/sem.2019. 71.2.165.

19. BIS, IS875:1987. Code of practice for design loads (other than earthquakes) for buildings and structures (Part 2-dead loads). Bureau of Indian Standards, New Delhi, 1987.

20. Shah, H. J. and Jain, S. K., Final report: A-Earthquake codes IITK-GSDMA project on building codes (design example of a six storey building), IITK-GSDMA-EQ26-V3.0, Indian Institute of Technology, Kanpur, 2008.

21. BIS, IS875:1987, Code of practice for design loads (other than earthquakes) for the buildings and structures (Part 1 -imposed loads). Bureau of Indian Standards, New Delhi, 1987.

22. NPTEL, Numerical problems on singly reinforced rectangular beams; Indian Institute of Technology, Kharagpur, 2009; https://nptel.ac.in/courses/105105104/6.

23. BIS, SP:16-1980, Design aids for reinforced concrete to IS-456:1978, Bureau of Indian Standards, New Delhi, 1980.

24. Ranganathan, R., Reliability Analysis and Design of Structures, Tata McGraw-Hill, New Delhi, 1990.

25. ACI, Building code requirements for structural concrete and commentary. ACI 318-11, American Concrete Institute, Chicago, USA, 2011.

26. COMREL Version 9, RCP GmbH, 2016; www.strurel.de

27. ISO, Bases for the design of structures - assessment of existing structures. ISO 13822, International Organization for Standardization, Geneva, 2010.

28. Chinese Standards, Structures GB 50068-200. Unified Standard for Reliability Design of Building, Beijing, China, 2011.

Received 26 March 2020; revised accepted 23 June 2020

doi: $10.18520 / \mathrm{cs} / \mathrm{v} 119 / \mathrm{i} 6 / 944-953$ 